кандидат юридических наук, PhD, профессор кафедры конституционного и муниципального права

Тюменского государственного университета

\section{О ПОНЯТИИ «МИРНЫЙ ПРОТЕСТ» В ПРАКТИКЕ ЕВРОПЕЙСКОГО СУДА ПО ПРАВАМ ЧЕЛОВЕКА}

Аннотация:

В статье категория «мирный протест» рассмотрена с точки зрения практики Европейского суда по правам человека. В предмет изучения входят основные подходы к осмыслению протестных отношений в аспекте юриспруденции. Объектом анализа являются протестные отношения, выражаемые при помощи права на мирные собрания, гарантированного в cm. 11 Европейской конвенции о защите прав человека и основных свобод. Подробному разбору подвергаются различия между понятиями «мирные собрания» и «массовые беспорядки». Работа выполнена с помощью формально-юридических методов анализа практики Европейского суда по правам человека. Несмотря на то что протест как социальное явление исследуется в основном в областях социологии, конфликтологии, истории и политологии, данный анализ протестных отношений проводится в юридическом поле. Новизна предпринятого исследования заключается в подходе к пониманию протестных отношений с позиций юридических наук. Основные выводы по результатам анализа практики Европейского суда по правам человека в области защиты права на выражение мирного протеста также обладают элементами научной новизны.

Ключевые слова:

политические права, право на мирные собрания, политический протест, конструктивное протестное поведение, Европейский суд по правам человека.
PhD in Law, Professor, Constitutional and Municipal Law Department, Tyumen State University

\section{THE CONCEPT OF PEACEFUL PROTEST IN THE CASE-LAW OF THE EUROPEAN COURT OF HUMAN RIGHTS}

\begin{abstract}
Summary:
This research deals with the category of peaceful protest as it is interpreted by the European Court of Human Rights. The author studies the main approaches in jurisprudence towards understanding protest relationships, implemented by virtue of the right to peaceful assembly guaranteed by the European Convention for the Protection of Human Rights and Fundamental Freedoms. The distinction between the concepts of peaceful assemblies and riots is explored. The method of formal logical analysis of the case-law by the European Court of Human Rights is mostly relied upon. Although the concept of protest as a social phenomenon is a matter of studies in sociology, conflictology, history or political science, the author undertakes the legal analysis of it. Thus, it is primarily legal understanding of protest that represents the added value of this research. Besides, the conclusions summarizing the analysis of the case-law by the European Court of Human Rights with respect to protecting the opportunity for peaceful protest are noteworthy as well.
\end{abstract}

Keywords: political rights, right to peaceful assembly, political protest, constructive protest behavior, European Court of Human Rights.

Основополагающие источники международного права, включая Европейскую конвенцию о защите прав человека и основных свобод [1], закрепляют за индивидами ряд прав и свобод, позволяющих выражать протест либо недовольство решениями или действиями органов публичной власти [2]. Как в юриспруденции, так и в остальных социальных науках исследования мирного характера политического протеста наиболее часто ассоциируются с массовыми протестными акциями, реализуемыми с помощью права на мирные собрания. Соответственно, в настоящей статье протестные отношения рассматриваются с точки зрения реализации права на мирное собрание, гарантированного в ст. 11 Европейской конвенции. В толковании положений ст. 11 этого документа, применяемых в практике Европейского суда по правам человека (далее - Европейского суда), используется термин «мирный протест» по отношению к ненасильственным способам выражения несогласия по вопросам, представляющим общественный интерес. Актуальность данного анализа объясняется тем, что действующее законодательство РФ не закрепляет дефиниции понятия «массовые беспорядки», поэтому важно учитывать интерпретацию Европейского суда. Таким образом, при разрешении судами дел об ограничении протестного поведения граждан необходимо юридически верно определить направленность, характер и значение действий протестующих.

Несмотря на то что протест как социальное явление исследуется в основном в области социологии, конфликтологии, истории и политологии, анализ протестных отношений проводится и учеными-правоведами. В отечественной юриспруденции научные представления о мирных формах протеста были знакомы еще дореволюционному государственному праву. Например, Б.Н. Чи- 
черин в «Курсе государственной науки» выступал за идею сдерживания протестов в ненасильственных рамках их выражения [3]. Постановка и дальнейшая разработка проблематики выражения политического протеста в современных правовых рамках осуществлены прежде всего С.А. Авакьяном, который исследует всю полноту протестных отношений в публичном праве [4].

В зарубежной литературе некоторые исследователи придерживаются мнения, что право на протест охватывается правом на свободу собраний. Например, Д. Делла Порта, А. Петерссон и Г. Рейтер утверждают, что «право на протест в Европе защищено в ст. 11 Европейской конвенции о правах человека... и ст. 12 Хартии прав человека ЕС, гарантирующей свободу мирных собраний и объединений» [5]. Можно встретить и более широкое понимание, в соответствии с которым мирный протест регулируется правом на свободу выражения мнений и правом на собрания и объединения согласно ст. 10 и 11 Европейской конвенции соответственно [6].

Европейская конвенция о защите прав человека и основных свобод закрепляет общие рамки реализации протестного поведения путем перечисления оснований ограничения гражданско-политических прав, которые необходимы в демократическом обществе и должны основываться на положениях закона. В соответствии со ст. 11:

«1. Каждый имеет право на свободу мирных собраний и свободу объединения с другими, включая право создавать профессиональные союзы и вступать в таковые для защиты своих интересов.

2. Осуществление этих прав не подлежит никаким ограничениям, кроме тех, которые предусмотрены законом и необходимы в демократическом обществе в интересах национальной безопасности и общественного порядка, в целях предотвращения беспорядков и преступлений, для охраны здоровья и нравственности или защиты прав и свобод других лиц. Настоящая статья не препятствует введению законных ограничений на осуществление этих прав лицами, входящими в состав вооруженных сил, полиции или административных органов государства».

В частности, В.Е. Чиркин пишет о том, что государство регулирует формы протеста и давления разных социальных слоев и групп, «устанавливая порядок проведения собраний, митингов, пикетов, демонстраций» [7]. Указанные положения, закрепленные в ст. 11 Европейской конвенции о защите прав человека и основных свобод, соответственно, отражены в тексте ст. 31 Конституции Российской Федерации, гарантирующей право на мирные собрания, и федерального закона от 19.06.2004 г. № 54-Ф3 «О собраниях, митингах, демонстрациях, шествиях и пикетированиях» [8]. Мирный характер протестного поведения обеспечивается запретительными нормами уголовного и административного права. Наиболее серьезные правовые последствия за несоблюдение рамок мирного протестного поведения в ходе публичных мероприятий предусмотрены в ст. 212 Уголовного кодекса РФ «Организация и участие в массовых беспорядках», за нарушение которой максимальное наказание составляет лишение свободы на срок до 8 лет.

Насильственные способы протестного поведения не охватываются правовой защитой. Европейский суд по правам человека не раз подчеркивал, что в ст. 11 Европейской конвенции защищено право только на «мирные» собрания. Это понятие не распространяется на демонстрации, участники и организаторы которых имеют насильственные намерения [9].

Государства обладают и определенной свободой усмотрения по отношению к выбору мер регулирования протестного поведения, что тоже представляет собой широкую категорию, находящуюся в зависимости от необходимости балансирования между разными целями в конкретной конфликтной ситуации. При этом вмешательство полиции, направленное на пресечение манифестаций протеста, хотя и ненасильственного, но ставящего в опасность здоровье протестующих, рассматривается Европейским судом как оправданное ограничение. В деле Сиссе против Франции группа мигрантов в знак протеста устроила голодовку в одной из церквей [10]. Почти 2 месяца протестующие находились в церкви, не препятствуя другим людям ее посещать, не нарушая общественный порядок, что было оценено как «мирный протест» (§ 52). Тем не менее действия правоохранительных органов, которые пресекли эту голодовку, не нарушили права на мирное собрание, поскольку длительная голодовка поставила в опасность здоровье демонстрантов (§ 51).

Выбор в пользу конструктивных, ненасильственных, правовых способов протеста означает выражение приверженности идеалам и принципам уважения прав человека. Анализ практики Европейского суда позволяет сделать вывод о том, что категория «мирный протест» включает в себя проявления протеста в ненасильственных формах. По мнению Европейского суда, мирным протестом выступают, например, такие действия, как выкрикивание лозунгов во время публичных мероприятий [11], воспрепятствование охоте на животных в знак протеста против охоты [12], а также запирание внутри помещений администрации президента в условиях, когда вопрос, являющийся предметом протеста, обладает признаком насущной общественной значимости [13].

Сложность при ограничении протестного поведения представляет и оценка риска перерастания мирных протестных акций в массовые беспорядки. Сам по себе данный риск не выводит такое публичное мероприятие из-под действия ст. 11 Европейской конвенции о защите прав человека и основных свобод [14]. Европейский суд в практике указывает на то, что признак наличия 
изначального умысла на совершение насильственных действий характеризует массовые беспорядки [15]. В деле Я. Белоусова против России, представляющем собой одно из последних решений в рамках «Болотного дела», Европейский суд подробно рассмотрел основные критерии отнесения действий граждан во время публичных мероприятий к массовым беспорядкам [16]. Вопрос о том, являлись ли таковыми действия заявителя при участии в протестной демонстрации 06.05.2012 г. на Болотной площади г. Москвы, выражал существо данного дела. В ходе демонстрации участники предприняли попытку прорыва через полицейское оцепление, в ходе которого заявитель использовал предмет шарообразной фрормы, поднятый с земли. Эти действия, по мнению суда, были вызваны неожиданным изменением маршрута шествия демонстрантов, которые сидели в ожидании на земле, спровоцировав большое скопление людей. Суд пришел к выводу, что изначально протестовавшие граждане не были нацелены на насильственные действия против полиции и других граждан, пострадавших во время прорыва оцепления. Этому выводу способствовали следующие доводы: 1) доказательства того, что прорыв полицейского оцепления входил в намерения организаторов протестной акции, отсутствуют в деле; 2) причиной сидячей забастовки была незапланированная смена маршрута митинга, о которой полиция организаторов не уведомила; 3) досмотр граждан на подходах к месту проведения митинга не выявил наличия у протестующих оружия или иных вызывающих тревогу предметов; 4) тот самый предмет желтого цвета и шарообразной формы, подобранный с земли заявителем, «по-видимому, был безобидным» (§ 171). Суд отметил, что акцент при квалификации протестного поведения должен быть сделан на том, чтобы установить, что протестующие «не призывали к насилию» и «не демонстрировали признаков того, что они готовы к нему прибегнуть» (§ 171). Такой же позиции, в соответствии с которой насилие, имевшее место в ходе публичного мероприятия, само по себе не означает, что произошедшие события входили в изначальный умысел протестующих, Европейский суд придерживался, например, в деле Гюн против Турции [17].

Превышение пределов мирного протеста было установлено Европейским судом в деле Карпюк и другие против Украины [18]. В рамках протестных демонстраций, изначально запланированных как мирные акции, возникла ситуация, в которой демонстранты прорывались через полицейское оцепление. Трое из них допустили насильственные действия против полиции. Отсутствие у протестующих изначального насильственного умысла было установлено. Поэтому в отношении троих заявителей, не допустивших фрактических насильственных действий против полиции, суд усмотрел нарушение права на мирное собрание, поскольку их осудили за организацию и участие в массовых беспорядках. В отношении других троих демонстрантов, которые совершили «акты насилия», Европейский суд постановил, что «заявители переступили границы мирного протеста» (§ 240) и, следовательно, соразмерные совершенным правонарушениям действия полиции по «пресечению агрессивного поведения» были обоснованны (§ 241).

Таким образом, в рамках международно-правового поля остаются только мирные акты протеста, не допускающие нарушений общественного и правового порядка в ходе выражения несогласия с решениями или действиями органов публичной власти. Ученый Х.М. Телла предлагает использовать критерий «повиновение» для разграничения народных восстаний и политического протеста. Согласно мнению этого исследователя, в отличие от гражданского неповиновения политический протест - это возражение, основанное на общем принятии системы. Индивид повинуется системе, либо принимая ее, либо обходясь без такого принятия (в силу, например, конформизма или страха). Насильственные фрормы протеста означают свержение существующего порядка, приводящее к системному кризису в результате неповиновения [19]. Данное требование отражено в Преамбуле к Всеобщей декларации прав человека. В ней подчеркивается: «необходимо, чтобы права человека охранялись властью закона в целях обеспечения того, чтобы человек не был вынужден прибегать в качестве последнего средства к восстанию против тирании и угнетения» [20]. Следовательно, народные восстания - это «вынужденные» и «последние» средства протеста именно против «тирании и угнетения», а не против законно избранных органов власти.

При работе над текстом Декларации рабочие группы рассматривали несколько вариантов отсылок к понятию «народное восстание». Первый проект 1947 г. даже содержал статью под названием «Право на сопротивление притеснению и тирании». Тем не менее специальная комиссия Генеральной Ассамблеи ООН приняла решение включить упоминание о таком сопротивлении в текст Преамбулы, тем самым лишая его статуса самостоятельного права человека. Насильственные акты гражданского неповиновения представляют собой фактические действия, осознанно предпринимаемые гражданами пусть и с морально оправданной целью, но с направленностью на нарушение действующих правовых норм [21]. Всеобщая декларация оставляет возможность революций открытой, подчеркивая, что охрана прав человека властью закона является единственным средством, способным их предотвратить. Соответственно, немногие национальные конституции гарантируют право на сопротивление против тех, кто предпринимает попытку устранить установленный в государстве строй и посягнуть на демократический порядок управления [22]. 
Таким образом, в интерпретации Европейского суда по правам человека категорией «мирный протест» охватывается широкий круг протестных акций. Главным критерием отграничения мирных протестных акций от массовых беспорядков является отсутствие умысла на совершение насильственных действий при планировании публичного мероприятия. При этом риск перерастания мирных протестов в массовые беспорядки всегда присутствует. Если протестующие допустили незапланированные насильственные действия в ходе публичного мероприятия, это не должно лечь в основу обвинений их в организации и участии в массовых беспорядках.

\section{Ссылки и примечания:}

1. Конвенция о защите прав человека и основных свобод ETS № 005 : принята 4 нояб. 1950 г. : с изм. и доп. от 21 сент. 1970 г., 20 дек. 1971 г., 1 янв. 1990 г., 6 нояб. 1990 г., 11 мая 1994 г. // Бюллетень международных договоров. 2001. № 3.

2. Статья подготовлена в рамках гранта Президента Российской Федерации «Конструктивный протест как механизм реализации права на участие в управлении делами государства» № МК-4880.2016.6.

3. Чичерин Б.Н. Курс государственной науки. В 3 т. М., 1894.

4. Авакьян С.А.: 1) Демократия протестных отношений: конституционно-правовое измерение // Конституционное и муниципальное право. 2012. № 1. С. 3-17 ; 2) Публичная власть: конституционно-правовые аспекты // Вестник Тюменского государственного университета. 2009. № 2. С. 7-8.

5. Policing of Transnational Protest / ed. by D. Della Porta, A. Peterson, H. Reiter. Abingdon, 2006. P. 157

6. Mead D. A Chill through the Back Door? The privatised regulation of peaceful protest // Public Law. 2013. Jan. P. 101

7. Чиркин В.Е. Публичное управление : учебник для студентов высших учебных заведений. М., 2004. С. 132.

8. О собраниях, митингах, демонстрациях, шествиях и пикетированиях : фредер. закон от 19 июня 2004 г. № $54-\Phi 3$ : в ред. от 7 июня 2017 г. // Собрание законодательства РФ. 2004. № 25. Ст. 2485.

9. Stankov and the United Macedonian Organisation Ilinden vs Bulgaria [Электронный ресурс] : жалобы № 29221/95, 29225/95 // Избранные решения Европейского суда по правам человека. Статья 11 Европейской конвенции о защите прав человека и основных свобод. С. 173-183. § 77. URL: https://www.mhg.ru/sites/default/files/files/11eszz.pdf (дата обращения: 01.12.2017); Galstyan vs Armenia [Электронный ресурс] : жалоба № 26986/03 // Там же. С. 146-150. § 101.

10. Cisse vs France [Электронный ресурс] : жалоба № 51346/99 // Избранные решения Европейского суда по правам человека ... С. 172.

11. Hyde Park and others vs Moldova [Электронный ресурс] : nos. 5. 6 : appl. nos. 6991/08, 15084/08. URL: http://echr.ketse.com/doc/6991.08-15084.08-en-20100914/view (дата обращения: 01.12.2017).

12. Steel and Others vs the United Kingdom [Электронный ресурс] : 23 Sept. 1998. URL: http://www.internationalhumanrightslexicon.org/hrdoc/docs/echrsteel.pdf (дата обращения: 01.12.2017).

13. Taranenko vs Russia [Электронный ресурс] : жалоба № 19554/05 : постановление Европейского суда по правам человека от 15 мая 2014 г. // Прецеденты Европейского суда по правам человека. 2014. № 9. С. 3-29. § 71, 97. URL: http://files.sudrf.ru/2176/norm_akt/doc20141128-084338.pdf (дата обращения: 01.12.2017).

14. Schwabe and M.G. vs Germany [Электронный ресурс] : жалобы № 8080/08, 8577/08 : постановление Европейского суда по правам человека от 1 дек. 2011 г. Доступ из справ.-правовой системы «Гарант».

15. Stankov ... ; Yaroslav Belousov vs Russia [Электронный ресурс] : жалобы № 2653/13, 60980/14 : постановление Европейского суда по правам человека от 4 окт. 2016. § 168. Доступ из справ.-правовой системы «Гарант».

16. Yaroslav Belousov ...

17. Gün and Others vs Turkey [Электронный ресурс] : жалоба № 8029/07 : постановление Европейского суда по правам человека от 18 июня 2013 г. § 50. Доступ из справ.-правовой системы «Гарант».

18. Karpyuk and others vs Ukraine [Электронный ресурс] : жалобы № 30582/04, 32152/04 : постановление Европейского суда по правам человека от 6 окт. 2015 г. URL: http://www.bailii.org/eu/cases/ECHR/2015/835.html (дата обращения: 01.12.2017).

19. Falcón y Tella M.J. A Three-Dimensional Theory of Law. Leiden, 2010. P. 274.

20. Всеобщая декларация прав человека : принята Генеральной Ассамблеей ООН 10 дек. 1948 г. // Российская газета. 1995. 5 апр.

21. См., например: Falcón y Tella M.J. Op. cit. P. 266, 271.

22. Согласно, например, ч. 4 ст. 20 Конституции Германии, «если иные средства не могут быть использованы, все немцы имеют право на сопротивление любому, кто предпринимает попытку устранить этот строй». В соответствии с ч. 4 ст. 120 Конституции Греции, «соблюдение Конституции вверяется патриотизму греков, которые правомочны и обязаны оказывать сопротивление всеми средствами всякой попытке отменить ее путем насилия». Следуя ст. 23 Хартии основных прав и свобод, которая является составной частью Конституции Чехии, «граждане имеют право оказывать сопротивление каждому, кто посягает на демократический порядок осуществления прав человека и основных свобод, установленный Хартией, если деятельность конституционных органов и действенное использование средств, предусмотренных законом, оказываются невозможными».

\section{References:}

Avakyan, SA 2009, 'Public authority: constitutional and legal aspects', Vestnik Tyumenskogo gosudarstvennogo universiteta, No. 2, pp. 7-8, (in Russian).

Avakyan, SA 2012, 'Democracy of protest relations: constitutional and legal dimension', Konstitutsionnoye i munitsipal'noye pravo, No. 1, pp. 3-17, (in Russian).

Chicherin, BN 1894, The course of state science, in 3 vols., Moscow, (in Russian).

Chirkin, VE 2004, Public management, textbook, Moscow, p. 132, (in Russian).

'Cisse vs France: appl. no. 51346/99' 2017, Izbrannyye resheniya Yevropeyskogo suda po pravam cheloveka. Stat'ya 11 Yevropeyskoy konventsii o zashchite prav cheloveka i osnovnykh svobod, p. 172, viewed 01 December 2017 , $<$ https://www.mhg.ru/sites/default/files/files/11eszz.pdf>, (in Russian). 
'Convention for the Protection of Human Rights and Fundamental Freedoms ETS No. 005 adopted on November 4, 1950 as amended and supplemented on September 21, 1970, December 20, 1971, January 1, 1990, November 6, 1990, May 11, 1994' 2001, Byulleten' mezhdunarodnykh dogovorov, No. 3, (in Russian).

Della Porta, D, Peterson, A \& Reiter, H (eds.) 2006, Policing of Transnational Protest, Abingdon, p. 157.

Falcón y Tella, MJ 2010, A Three-Dimensional Theory of Law, Leiden, p. 274

'Galstyan vs Armenia: appl. no. 26986/03' 2017, Izbrannyye resheniya Yevropeyskogo suda po pravam cheloveka. Stat'ya 11 Yevropeyskoy konventsii o zashchite prav cheloveka i osnovnykh svobod, pp. 146-150, § 101, viewed 01 December 2017, $<$ https://www.mhg.ru/sites/default/files/files/11eszz.pdf>, (in Russian).

Hyde Park and others vs Moldova: nos. 5. 6: appl. nos. 6991/08, 15084/08 2017, viewed 01 December 2017, <http://echr.ketse.com/doc/6991.08-15084.08-en-20100914/view>.

Karpyuk and others vs Ukraine: appl. nos. 30582/04, 32152/04: the decision of the European Court of Human Rights of 6 October 2015 2017, viewed 01 December 2017, <http://www.bailii.org/eu/cases/ECHR/2015/835>.

Mead, DA 2013, 'Chill through the Back Door? The privatized regulation of peaceful protest', Public Law, January, p. 101.

'Stankov and the United Macedonian Organization Ilinden vs Bulgaria: appl. nos. 29221/95, 29225/95' 2017, Izbrannyye resheniya Yevropeyskogo suda po pravam cheloveka. Stat'ya 11 Yevropeyskoy konventsii o zashchite prav cheloveka i osnovnykh svobod, pp. 173-183, § 77, viewed 01 December 2017, <https://www.mhg.ru/sites/default/files/files/11eszz.pdf>, (in Russian).

Steel and Others vs the United Kingdom: 23 Sept. 1998 2017, viewed 01 December 2017, <http://www.internationalhumanrightslexicon.org/hrdoc/docs/echrsteel.pdf>.

'Taranenko vs Russia: appl. no. 19554/05: judgment of the European Court of Human Rights of 15 May 2014' 2014, Pretsedenty Yevropeyskogo suda po pravam cheloveka, No. 9, pp. 3-29, § 71, 97, viewed 01 December 2017, URL: <http://files.sudrf.ru/2176/norm_akt/doc20141128-084338.pdf>, (in Russian). 